Acta Scientiae Veterinariae.33(1): 1-16,2005.

\title{
Produção in vitro de embriões ovinos
}

\author{
In vitro production of ovine embryos
}

Mari Lourdes Bernardi ${ }^{1}$

\begin{abstract}
RESUMO
A produção in vitro (PIV) de embriões compreende as etapas de maturação dos oócitos, capacitação dos espermatozóides, fecundação dos oócitos e cultivo dos zigotos até o estádio de mórula ou blastocisto. Embora a execução destas etapas não seja complexa, vários fatores podem interferir no seu sucesso. Se uma das etapas não é realizada corretamente, uma redução do índice de sucesso na etapa seguinte pode ocorrer. Nesta revisão são detalhadas as etapas referentes à PIV de embriões ovinos, sendo enfocados a eficiência de cada uma e os avanços obtidos. Também são enfatizados os aspectos que devem ser melhorados para que as tecnologias associadas à PIV de embriões ovinos tenha uma aplicação mais difundida.
\end{abstract}

Descritores: in vitro, PIV, embriões, ovinos.

\section{ABSTRACT}

In vitro embryo production (IVP) comprises oocyte maturation, sperm capacitation, oocyte fertilization and culture of zygotes up to morula or blastocyst stages. Carrying out these procedures is not complex, but their success depends on several factors. If one of them is not successfully performed, a detrimental effect on the efficiency of the following step can arise. In this review, the procedures concerning IVP of ovine embryos are detailed, being focused overall efficiency and advances obtained. Emphasis is put on aspects needing an improvement so that technologies related to IVP of ovine embryos have a widespread application.

Key words: in vitro, IVP, embryos, ovines. 


\section{INTRODUÇÃO}

\section{ORIGEM E OBTENÇÃO DOS OÓCITOS}

\section{MATURAÇÃo dOS OÓCITOS}

\section{SELEÇÃO E CAPACITAÇÃ̃o DOS ESPERMATOZÓIDES}

\section{FECUNDAÇÃo dos OóCITOS}

\section{Cultivo dos EMbriões}

\section{Efeito da tensão de oxigênio}

2. Efeitos dos aminoácidos

\section{Efeito do soro}

4. Efeito da glicose

5. Velocidade de desenvolvimento in vitro conforme o sexo

\section{ProduÇão IN VITRo de EMbriões A PARTIR dE FÊMEAS PRÉ-PÚBERES}

\section{QUALIDADE DOS EMBRIÕES OVINOS PRODUZIDOS IN VITRO}

\section{TRANSFERÊNCIA DE EMBRIÕES OVINOS PRODUZIDOS IN VITRO}

\section{Problemas gestacionais e perinatais}

\section{Conclusões}

\section{INTRODUÇÃO}

Nos meados da década de 80 foram obtidos os primeiros cordeiros oriundos da fecundação in vitro (FIV) de oócitos ovinos maturados in vitro [14] ou maturados in vivo [16]. Alguns anos mais tarde, foi relatado o nascimento do primeiro cordeiro [17] oriundo da realização de todas as etapas in vitro, isto é, desde a maturação dos oócitos até o desenvolvimento de mórulas.

A PIV de embriões ovinos ainda mantém um caráter experimental acentuado, mas dos estudos efetuados com a espécie ovina resultaram contribuições significativas para a PIV de embriões de outras espécies, principalmente no que diz respeito aos sistemas de cultivo in vitro. Por exemplo, os benefícios do cocultivo de embriões com células do oviduto e da redução da concentração de oxigênio foram constatados com embriões ovinos e, posteriormente, utilizados com embriões de outras espécies de interesse zootécnico. Além de poder ser fonte de embriões para pesquisas básicas de biologia e fisiologia do desenvolvimento, a produção in vitro de embriões ovinos possui bom potencial para a aplicação no melhoramento genético de rebanhos ovinos, bem como na produção de clones e animais transgênicos.

\section{ORIGEM E OBTENÇÃO DOS OÓCITOS}

Os oócitos utilizados para a PIV de embriões ovinos podem ser obtidos de fêmeas adultas ou de fêmeas pré-púberes, as quais são submetidas ou não a tratamento hormonal prévio.

O tratamento hormonal, visando estimular o crescimento folicular e obtenção de um maior número de oócitos por ovário, é indicado principalmente para fêmeas pré-púberes, fêmeas em anestro estacional ou para fêmeas geneticamente superiores. O protocolo de estimulação hormonal em fêmeas adultas pode ser efetuado de várias maneiras: uso de FSH (3 aplicações de 4-5mg cada, efetuadas 48, 40 e $24 \mathrm{~h}$ antes do abate), cujo tratamento inicia entre o $8^{\circ}$ e $10^{\circ}$ dia do ciclo estral [16,17]; aplicação de FSH juntamente com o uso de gestágenos [60], ou aplicação única de eCG [22].

Durante a estação reprodutiva normal [22], a qualidade dos oócitos e a taxa de oócitos que alcançaram metáfase II foi semelhante entre fêmeas estimuladas com eCG (84\%) e aquelas não estimuladas 
(89\%). No entanto, a estimulação hormonal prévia parece mais importante quando a FIV é efetuada durante o anestro estacional [60], visto as maiores taxas de clivagem obtidas a partir de oócitos de fêmeas estimuladas com FSH (61\%), em comparação aos de fêmeas não estimuladas (43\%).

Sobretudo em condições experimentais, os ovários são obtidos após o abate das ovelhas, sem estimulação hormonal prévia. Nesse caso, os ovários são transportados, do abatedouro até o laboratório, em meio PBS ou em solução $\mathrm{NaCl}$ 0,9\%, com antimicrobianos.

A obtenção dos oócitos pode ser efetuada pela dissecção dos folículos com 2 a $6 \mathrm{~mm}$ de diâmetro ou pela aspiração com agulhas acopladas a seringas ou a bombas de vácuo, estas últimas sendo importantes, no caso de aspiração por laparoscopia. A dissecção dos folículos permite a obtenção de grande número de oócitos (20-40/ovário), mas apresenta a desvantagem de ser demorada, além da necessidade de maior treinamento do indivíduo que a efetua. O procedimento de aspiração é simples e rápido, embora o número de oócitos obtidos seja inferior (37/ovário) ao da dissecção. No entanto, o método de aspiração passou a ser o de eleição para a obtenção de oócitos de fêmeas ovinas, após o abate.

Em geral, em fêmeas previamente estimuladas com hormônios, o número de oócitos obtidos é maior do que aquele obtido de fêmeas não estimuladas, independentemente do método utilizado. Utilizando a aspiração [54], maior número de oócitos foi obtido de fêmeas jovens estimuladas (16-36/ovário) em comparação às fêmeas adultas não estimuladas (3,5/ovário).

A coleta de oócitos por laparoscopia permite a produção de cordeiros a partir de fêmeas de alto valor genético, nas quais os procedimentos convencionais de produção e transferência de embriões não são aplicáveis, como é o caso de fêmeas pré-púberes, gestantes, fêmeas com infertilidade temporária ou irreversível $[4,39]$. Além de permitir a coleta de oócitos durante o anestro estacional $[39,66]$, a laparoscopia possui a vantagem de não ser traumática como a laparotomia, sem sequielas ou efeitos negativos na fertilidade futura das fêmeas doadoras, mesmo em casos de 8 a 20 aspirações repetidas $[4,66]$.

Oócitos podem ser obtidos por laparoscopia de fêmeas que não são estimuladas com hormônios $[39,65]$, ou de fêmeas ovinas estimuladas com FSH/
LH, combinado ou não ao uso de eCG, 24 ou 48h antes da aspiração [4]. Também é utilizado FSH em dose única [1] ou em várias aplicações [58], injeção única de eCG, 48h antes da aspiração [62], a qual pode ser associada à administração de anticorpos monoclonais anti-eCG, $\log$ após a aspiração $[1,66]$. Para fêmeas não estimuladas com hormônios foi relatada a obtenção de 4,6 [39] ou 6,9 [65] oócitos por sessão de aspiração. Maior número de oócitos pode ser obtido com duas [66] ao invés de uma aspiração por semana $(7,5$ x 4,9 oócitos). Maior número de oócitos por sessão foi obtido quando as fêmeas foram estimuladas com eCG (7,0 x 4,9 oócitos), sendo possível, no entanto, obter aproximadamente o mesmo número de oócitos por semana, usando eCG e aspirando uma vez, ou aspirando 2 vezes por semana, sem estimulação hormonal (7,0 x 7,4 oócitos). No caso de fêmeas estimuladas com FSH ou FSH/LH, o número de oóctios obtido por sessão de aspiração foi de 10 a $11[4,58]$.

A taxa de recuperação (número de oócitos obtidos/número de folículos aspirados) situa-se entre 55 e $80 \%$ [3,4,39,58,66]. Dos oócitos obtidos, 60 a $80 \%$ são selecionados para os procedimentos de maturação e fecundação in vitro $[4,58,66]$. A taxa de fecundação de oócitos obtidos de ovários de matadouro é semelhante à observada com oócitos aspirados por laparoscopia de fêmeas estimuladas com hormônios [3].

\section{Maturação dos Oócitos}

Após a obtenção dos oócitos, aqueles que não apresentam expansão das células do cumulus, que possuem no mínimo 3 a 4 camadas de células da granulosa, citoplasma uniformente granulado e com coloração homogênea, nem muito clara e nem muito escura, são selecionados para a maturação.

O meio mais empregado para a maturação dos oócitos é o TCM 199, acrescido de 10\% de Soro Fetal Bovino (SFB). Apesar de células da granulosa, em concentrações variando de 2 a $5 \times 10^{6}$ células $/ \mathrm{mL}$ de meio de maturação, terem sido bastante utilizadas nos primeiros trabalhos de PIV de embriões ovinos, seu emprego diminuiu com o passar do tempo. A presença das mesmas não foi necessária para a maturação de oócitos obtidos de fêmeas estimuladas com FSH, durante o anestro estacional [60]. No entanto, estes mesmos autores observaram maiores taxas de clivagem quando oócitos de fêmeas não estimuladas com FSH foram maturados na presença de células da 
granulosa obtidas de folículos de fêmeas estimuladas (52\%), em comparação à utilização de células da granulosa de fêmeas não estimuladas (35\%) ou à ausência de células da granulosa (42\%).

$O$ volume de meio utilizado para a maturação varia de 50 a $500 \mathrm{~mL}$. Volumes menores $(25 \mathrm{~mL})$ podem ser utilizados quando menos do que 5 oócitos são obtidos por fêmea, por laparoscopia, e há a necessidade de maturá-los separadamente [65].

A maturação é geralmente efetuada na presença dos hormônios FSH $(0,1$ a 10mg/mL), LH (0,02 a $10 \mathrm{mg} / \mathrm{mL})$ e $17 \mathrm{~b}$-estradiol $(1 \mathrm{mg} / \mathrm{mL})$, durante 22 a $24 \mathrm{~h}$, em temperatura de $38,5-39^{\circ} \mathrm{C}$, com atmosfera de $5 \% \mathrm{CO}_{2}$ em ar, ou em atmosfera com a concentração de oxigênio reduzida para 7 ou $5 \%$. A presença de estradiol no meio de maturação possui efeito positivo nas taxas de clivagem e de formação de blastocistos, mas não seria necessário, caso líquido folicular estivesse presente [29]. A presença de gonadotrofinas parece indispensável para a maturação de oócitos oriundos de fêmeas imaturas, pois foi verificado [43] índice de metáfase II bem mais baixo na ausência (8\%) do que na presença de FSH/LH (76\%). Cabe ressaltar, no entanto, que essas fêmeas pré-púberes (30-40 dias de idade) não haviam sido previamente estimuladas com hormônios.

Quanto à inclusão de fatores de crescimento no meio de maturação, efeito positivo na retomada da meiose, clivagem e formação de blastocistos foi constatado na presença de EGF, mas não de IGF-I [29].

\section{SELEÇão E CAPACITAÇÃo DOS ESPERMATOZÓIDES}

A FIV pode ser realizada com sêmen fresco ou congelado. O sêmen fresco é utilizado principalmente quando machos de fertilidade comprovada estão disponíveis para a coleta. Sua utilização apresenta os inconvenientes da necessidade de coletar o(s) macho(s) a cada FIV e da utilização restrita ao grupo de pesquisadores que dispõem desses machos. A partir do relato de sucesso e da praticidade do uso de sêmen congelado [33], o mesmo foi incluído na maioria dos protocolos de FIV em ovinos. Não tem sido constatada diferença no número de oócitos fecundados, entre sêmen fresco e congelado, embora os zigotos fecundados com sêmen congelado estivessem mais avançados no desenvolvimento do que os fecundados com sêmen fresco [49]. Acredita-se que isto se deva às alterações nas membranas espermáticas em função do congelamento e descongelamento implicando, provavelmente, em menor tempo necessário para a capacitação dos espermatozóides.

A seleção dos espermatozóides é efetuada pelo método da migração ascendente (Swim-up), ou submetendo os espermatozóides a um gradiente de Percoll (45\%/90\%) e centrifugando-os durante 20 minutos a 500-700 g. O Swim-up consiste em depositar a amostra de sêmen no fundo de um tubo contendo o meio de capacitação e em recuperar, após 1 a 2h, o sobrenadante contendo os espermatozóides que migraram para a porção superior do meio. No método do Percoll, a separação dos espermatozóides viáveis baseia-se no fato de que os espermatozóides com membrana íntegra não perderam seu conteúdo celular e, sendo mais pesados, depositam-se no fundo do tubo após a centrifugação.

O meio mais utilizado para a seleção e a capacitação dos espermatozóides é o Defined Medium [12] modificado, denominado DM-Hepes [16]. Podem também ser utilizados os meios TCM 199, Tyrode's-Hepes ou SOF (Synthetic Oviduct Fluid), na maioria das vezes acrescidos de soro de ovelha em estro ou meta-estro. A concentração de espermatozóides utilizada durante a capacitação é, geralmente, de $1 \times 10^{7}$ espermatozóides $/ \mathrm{mL}$. O tempo de capacitação é 1 a $2 \mathrm{~h}$ [33].

\section{FECUNDAÇÃo dOS OÓCITOS}

A fecundação se processa a $38,5-39^{\circ} \mathrm{C}$, em geral em atmosfera contendo $5 \%$ de $\mathrm{CO}_{2}$. O meio DM-Hepes (pH 7,7) é bastante utilizado para a fecundação, embora outros meios já tenham sido utilizados com sucesso, como é o caso do SOF $[28,32,33,70]$ e o Tyrode's-bicarbonato [80]. Não é habitual o uso de heparina para a FIV em ovinos e, em poucos casos, é relatado o uso de penicilamina e hipotaurina no meio de fecundação $[4,70]$.

A remoção parcial das células do cumulus é efetuada, após breve contato dos oócitos maturados com solução de hialuronidase (150 IU/mL), antes de colocá-los em contato com os espermatozóides. As células são geralmente removidas por pipetagens suaves e repetidas dos oócitos, com pipeta de diâmetro ligeiramente superior àquele do oócito.

Não é incomum o uso de espermatozóides oriundos de uma mistura de ejaculados de 2 a 4 car- 
neiros. Essa estratégia visa evitar baixas taxas de fecundação devido ao possível efeito específico de algum macho, em função da variabilidade existente entre os mesmos [20,53]. No entanto, a utilização de sêmen de um só macho, para cada conjunto de oócitos, é a recomendada quando a PIV for utilizada como procedimento para acelerar o melhoramento genético de rebanhos ovinos.

Mesmo tendo sido constatada a possibilidade de utilizar 0,1 a 0,5 milhão de espermatozóide/mL, na fecundação [49], a concentração utilizada mais comumente é a de 1 milhão. Os oócitos e espermatozóides permanecem juntos, no meio de fecundação, por 15 a 24h, antes de serem cultivados in vitro.

Alguns estudos têm sido efetuados a fim de melhorar as condições de fecundação, aumentar a taxa de clivagem e posterior desenvolvimento embrionário. Assim, o aumento da concentração de cálcio no meio DMH [36], bem como a inclusão de células do oviduto durante a fecundação [33] resultaram em aumento das taxas de fecundação e de clivagem. Duas proteínas, denominadas SOP92 (92kDa e pI 5) e SOP46 (46 kDa e pI 4-5,2), foram isoladas da secreção do oviduto, no período peri-estral (do estro até 4-5 dias após). Elas fixam-se à zona pelúcida, atravessam-na e se associam aos blastômeros de embriões ovinos, não sendo mais detectadas quando o embrião entra no útero [23]. Tem sido constatado que todas as concentrações de uma fração de fluido tubárico, rica em uma glicoproteína estral ovina (90-92 kDa), utilizadas na fecundação de oócitos ovinos maturados in vitro, em meio contendo soro humano, proporcionaram aumento da taxa de clivagem bem como da proporção de blastocistos [32].

Por outro lado, quando o meio de fecundação continha soro de ovelha, somente a concentração de $10 \%$ resultou em aumento da taxa de clivagem, sem nenhum efeito benéfico na formação de blastocistos. Acredita-se que essa glicoproteína não seria essencial para o reconhecimento/fixação dos oócitos e espermatozóides, quando proteínas da mesma espécie estiverem presentes no meio de fecundação. $\mathrm{O}$ efeito dessa glicoproteína parece ser espécie-específico pois a mesma não apresentou efeito benéfico sobre a taxa de clivagem ou a produção de blastocistos, quando acrescentada ao meio de cultivo de zigotos bovinos fecundados in vitro [31].

\section{Cultivo dos EMbriões}

O desenvolvimento dos embriões até o estádio de mórula ou blastocisto é desejável para poder selecioná-los antes da transferência, reduzindo assim os custos com o número de receptoras utilizadas. Embora tenham sido feitos progressos, o cultivo in vitro (CIV) é ainda uma das etapas limitantes na PIV de embriões ovinos.

Quando cultivados em meios sinteticamente definidos, embriões de ruminantes apresentavam bloqueio no seu desenvolvimento, por ocasião do $4^{\circ}$ ciclo celular (8-16 células), coincidente com o momento da ativação do genoma embrionário [15,67]. Pelo fato desse bloqueio não ocorrer se os zigotos fossem incubados no oviduto de ovelhas [16,17], esse sistema foi preferencialmente utilizado, nos primeiros trabalhos de FIV em ovinos. Entretanto, um efeito benéfico do cocultivo sobre monocamadas de células epiteliais do oviduto foi observado com zigotos ovinos oriundos de maturação e fecundação in vivo [24], o que foi confirmado, posteriormente, para embriões ovinos produzidos in vitro $[9,80]$.

Embora maior desenvolvimento até o estádio de blastocisto [24], tenha sido observado para embriões fecundados in vivo, com o uso de células do oviduto (42\%) em comparação com fibroblastos fetais ovinos $(4,5 \%)$, vários tipos celulares podem ser utilizados para o cultivo de embriões de ruminantes. Essas observações sugerem que pelo menos parte do efeito do cocultivo é generalizado e deve-se a fatores estimuladores do crescimento que não são célula-específicos, ou pode significar que vários tipos celulares possuem a habilidade de purificar o ambiente de cultivo pela remoção de substâncias nocivas ao desenvolvimento dos embriões.

O metabolismo ou seqüestro de elementos prejudiciais ao desenvolvimento embrionário, como a amônia [25], ou mudanças de pH e tensão gasosa estão provavelmente relacionados com o efeito benéfico do cocultivo [6,37]. Além disso, os fatores de crescimento secretados pelas células podem ser benéficos para o desenvolvimento dos embriões.

A constatação do efeito benéfico do cocultivo com células do oviduto [24] dificultou a expansão do cultivo em meios sinteticamente definidos, na ausên- 
cia de células somáticas. Apesar de ter sido demonstrada a possibilidade de evitar o bloqueio in vitro, cultivando embriões ovinos fecundados in vivo, em meio simples e com redução da tensão de oxigênio, já no inicio da década de 70 [68], somente após quase duas décadas, esse efeito benéfico foi novamente comprovado $[27,71,78]$. Desta forma, o cultivo na ausência de células somáticas e sob tensão reduzida de oxigênio foi também empregado para os embriões fecundados in vitro sendo, hoje, o sistema preferencial de cultivo $[57,79]$. O meio de cultivo mais utilizado tem sido o SOF, acrescido de aminoácidos essenciais e não essenciais, BSA ou soro (Tabela 1).

\section{Efeito da tensão de oxigênio}

A necessidade da utilização de uma tensão de oxigênio reduzida, quando o cultivo é efetuado na ausência de células somáticas, foi confirmada pelo baixo desenvolvimento observado após o cultivo de zigotos ovinos fecundados in vitro, no meio SOF, com atmosfera contendo $20 \% \mathrm{O}_{2}$ ao invés de $5 \% \mathrm{O}_{2}[11,80]$. Além disso, foi constatado desenvolvimento mais rápido para os zigotos ovinos cultivados em SOF sob tensão reduzida de oxigênio, em comparação aos zigotos cultivados sob alta tensão de oxigênio, independentemente da presença ou não de células do oviduto [11].

\section{Efeito dos aminoácidos}

O emprego de meios simples e definidos permitiu a realização de estudos mais precisos para a determinação dos substratos importantes nas fases iniciais do desenvolvimento embrionário. Um exemplo disto foi a constatação da importância dos aminoácidos, tanto os essenciais como os não essenciais, na redução do bloqueio dos estádios de 8-16 células, durante o cultivo de zigotos ovinos fecundados in vivo [27]. Um efeito benéfico da suplementação do meio de cultivo com aminoácidos, reduzindo o tempo para a formação dos blastocistos e aumentando o número de células dos mesmos, também foi demonstrado para embriões ovinos produzidos in vitro [77]. Quando aminoácidos foram utilizados em concentrações semelhantes às existentes no oviduto de fêmeas ovinas em fase peri-ovulatória, os benefícios na formação de blastocistos ou na eclosão dos mesmos foram maiores do que a utilização de concentrações existentes nas preparações comerciais [77].

\section{Efeito do soro}

A inclusão de soro humano (SH), em concentrações que variam de 10 a $20 \%$, nos meios de cultivo de embriões ovinos, permite a obtenção de altas taxas de desenvolvimento até o estádio de blastocisto $[77,80]$.

Apesar das altas taxas de desenvolvimento, tem sido constatado maior número de inclusões lipídicas nos embriões cultivados na presença de $\mathrm{SH}$, em comparação aos cultivados na presença de BSA [70] Essas inclusões foram identificadas como osmofílicas e, provavelmente, contêm uma grande quantidade de lipídios insaturados. Além das inclusões lipídicas, foi observado que, na presença de $\mathrm{SH}$, os embriões apresentaram maior fragmentação citoplasmática e menor habilidade de compactação [77]. Não sabe-se ainda se o soro das outras espécies também produz essas alterações, pois praticamente não há comparações com o uso de BSA. Foi verificado que blastocistos ovinos PIV, na presença de soro de novilho, apresentaram menor número de células do que os produzidos na presença de BSA, embora não tenha havido diferenças nas taxas de clivagem e nas taxas de desenvolvimento até o estádio de blastocisto [41].

As altas taxas de blastocistos e de eclosão obtidas com o uso de BSA, sobretudo quando os aminoácidos são acrescentados em concentrações semelhantes às do oviduto [77], em associação com a redução nas perdas perinatais [70], comprovam que o SH não é necessário para o cultivo de embriões ovinos FIV.

\section{Efeito da glicose}

A presença de glicose no meio de cultivo é considerada um dos fatores que aumentam a fragmentação de zigotos ovinos quando cultivados in vitro [51]. Além de ter sido favorável para o cultivo de zigotos ovinos fecundados in vivo [44], redução da fragmentação e maior proporção de blastocistos foi obtida quando zigotos ovinos produzidos in vitro foram cocultivados durante as primeiras $48 \mathrm{~h}$ no meio CZB, o qual não contém glicose [9].

Um efeito inibidor da glicose, sobre as primeiras clivagens, tem sido demonstrado para zigotos de várias espécies. A utilização de glicose pelos embriões ovinos varia conforme o estádio de desenvolvimento, sendo relativamente baixa nos estádios precoces, com um primeiro aumento de sua utilização ocorrendo entre 8 e 16 células. Em seguida, um aumento 


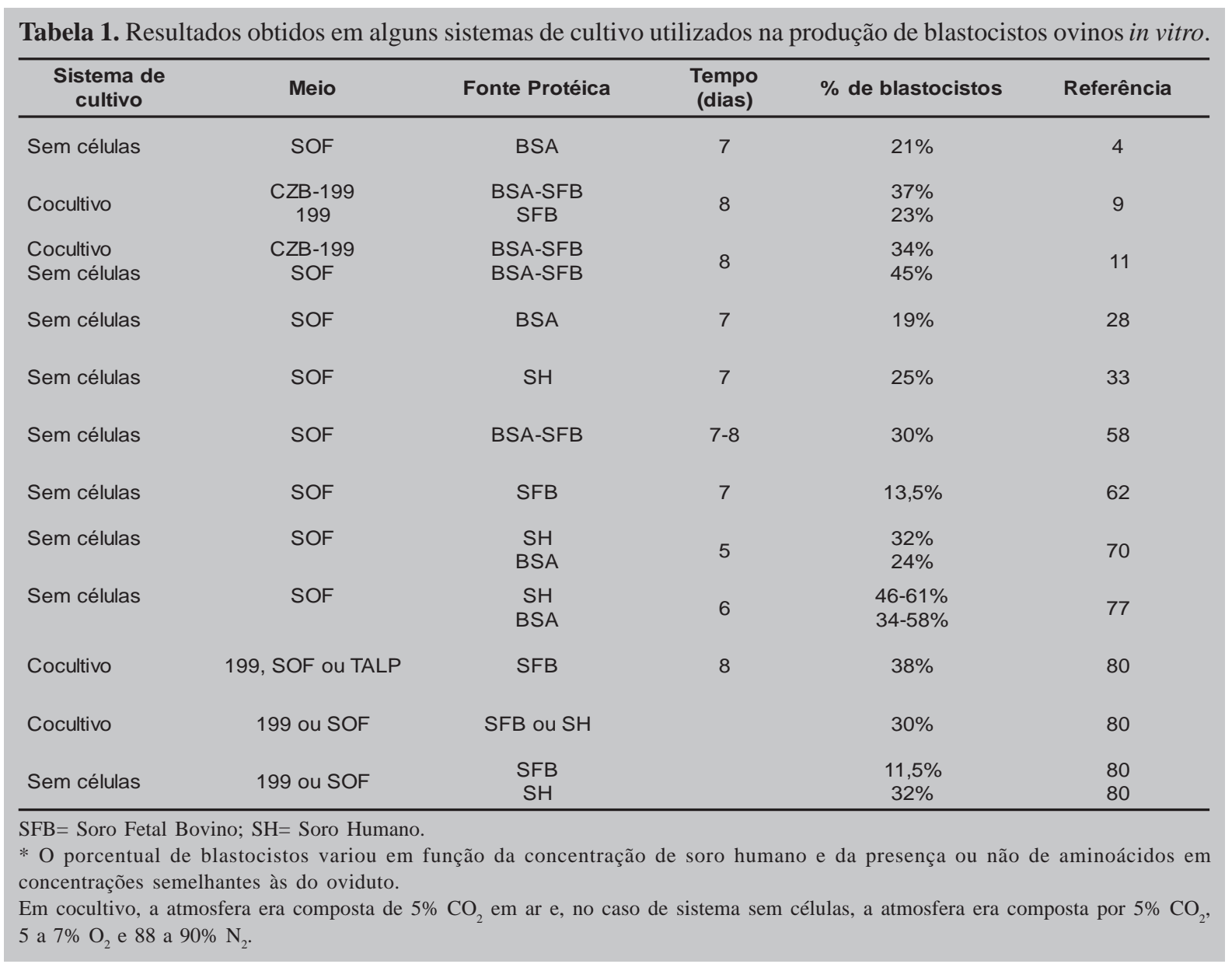

considerável do metabolismo da glicose ocorre entre os estádios de mórula e blastocisto expandido [26,73]. Assim, a glicose parece não ser a principal fonte de energia para os zigotos ovinos, os quais podem, nos 45 primeiros ciclos celulares, beneficiar da presença de piruvato, lactato ou mesmo de aminoácidos.

A severidade do efeito inibidor da glicose sobre o desenvolvimento de zigotos ovinos parece, então, variar em função da concentração de outros substratos energéticos, pois concentrações de glicose até $3 \mathrm{mM}$ não prejudicaram o desenvolvimento embrionário ovino, desde que piruvato e/ou lactato estivessem presentes no meio de cultivo [72]. De fato, bons índices de desenvolvimento foram observados em embriões ovinos FIV cultivados no meio SOF contendo $1,5 \mathrm{mM}$ de glicose, durante todo o período de cultivo [11].

\section{Velocidade de desenvolvimento in vitro conforme o sexo}

Na espécie bovina, os embriões de sexo masculino se desenvolvem in vitro mais rapidamente do que os de sexo feminino. A explicação para esse fenômeno continua polêmica e, enquanto uns argumentam que os embriões do sexo masculino apresentam um fator ligado ao cromossomo $\mathrm{Y}$ que lhe confere maior velocidade de desenvolvimento, outros sugerem que os mesmos seriam mais resistentes às condições adversas do cultivo in vitro. Um desvio na proporção dos embriões de cada sexo não foi observado quando embriões bovinos foram cultivados no oviduto, após FIV [30,42], o que indica que as condições in vitro contribuem para esse desvio. De fato, diferenças no número de células, favorecendo os embriões bovinos de sexo masculino, ocorrem na presença de glicose, mas não na sua ausência [13].

$\mathrm{Na}$ espécie ovina, ficou evidenciada a ocorrência de maior porcentual de machos no grupo de embriões PIV que alcançaram mais rapidamente o estádio de blastocisto [10]. Dentro deste grupo de embriões, maior porcentual de machos estava presente no grupo de blastocistos mais avançados (70\%), em comparação ao grupo dos menos avançados 
(42\%). Cabe salientar que, apesar deste desvio significativo, a proporção de machos nunca foi superior a $70 \%$ e que a proporção média de embriões do sexo masculino (56\%) não diferiu da taxa esperada de 50\%. Isto pode indicar que as condições de cultivo empregadas, principalmente no que se refere à baixa concentração de glicose e à ausência de soro nas primeiras $65 \mathrm{~h}$ de cultivo, podem ter contribuído para um desvio não tão acentuado na proporção de embriões do sexo masculino, reforçando as observações efetuadas com embriões bovinos PIV [13]. Por outro lado, a possível contribuição de genes ligados ao cromossomo Y não pode ser descartada, visto que a presença do gene ZFY foi detectada em embriões ovinos PIV, desde o estádio de 2 células [8].

\section{Produção in Vitro de EMbriões a PARTIR de FÊMEAS PRÉ-PÚBERES}

Nos últimos anos, tem havido um interesse crescente na utilização de fêmeas pré-púberes como doadoras de oócitos. A utilização de fêmeas jovens em programas de produção in vitro de embriões fornece a possibilidade de acelerar os ganhos genéticos do rebanho pela redução do intervalo entre gerações.

Fêmeas de várias idades (desde 3 semanas até 4-6 meses), bem como vários protocolos de estimulação hormonal, têm sido empregados nos estudos que avaliam as potencialidades do uso de oócitos de fêmeas jovens para a PIV. O número de oócitos recuperados por fêmea, bem como a capacidade de desenvolvimento in vitro até o estádio de blastocisto [19,54] dependem dos protocolos de estimulação hormonal utilizados. Apesar das taxas de maturação e de fecundação in vitro não terem diferido entre oócitos de fêmeas pré-púberes (3-6 semanas) e fêmeas mais velhas (16-24 semanas), a utilização de uma aplicação única de estrógeno + progesterona, antes da estimulação de fêmeas pré-púberes com gonadotrofinas, apresentou efeito benéfico, aumentando o percentual de blastocistos obtidos por oócito clivado [54]. Foi, também, constatado que a aplicação de FSH é mais eficaz do que a associação FSH-eCG, para a produção de blastocistos, a partir de oócitos de fêmeas ovinas de 4-5 semanas de idade [59].

Evidências sugerem que oócitos de fêmeas jovens possuem menor potencial para a produção de embriões do que oócitos de fêmeas adultas. De fato, maior incidência de polispermia e menor capacidade de desenvolvimento até o estádio de blastocisto foram observadas com oócitos oriundos de fêmeas prépúberes $[43,55,56]$. Apesar de diferenças na taxa de maturação não terem sido observadas pela maioria dos autores, há relato de menores proporções de oócitos de fêmeas pré-púberes (4 semanas de idade) alcançando o estádio de metáfase II, após $19 \mathrm{~h}$ de cultivo, em comparação aos oócitos obtidos de fêmeas adultas [46]. Também foi constatado que oócitos de fêmeas pré-púberes foram mais sensíveis ao intervalo entre o abate e processamento dos ovários, apresentando atraso na progressão meiótica mais acentuado do que os oócitos de fêmeas adultas, quando o tempo foi superior a $3 \mathrm{~h}$.

Algumas diferenças metabólicas e estruturais foram observadas entre oócitos de fêmeas jovens e os de fêmeas adultas. Oócitos obtidos de fêmeas pré-púberes apresentaram menor metabolismo da glutamina quando comparados aos oriundos de fêmeas adultas, após maturação in vivo ou in vitro, além de apresentarem mitocôndrias e grânulos corticais de menor tamanho [56]. Acreditase que essas alterações possam estar associadas a uma maturação citoplasmática inadequada, a qual poderia implicar em menor capacidade de desenvolvimento in vitro [55].

Utilizando oócitos de fêmeas pré-púberes com 30-40 dias de idade e que não haviam sido submetidas a tratamento hormonal prévio [43] foi constatado que, na ausência de gonadotrofinas, somente $8 \%$ dos oócitos alcançaram o estádio de metáfase II, em comparação com $58 \%$ para os oócitos obtidos de fêmeas adultas. Considerando que a maioria dos oócitos das fêmeas jovens apresentavam diâmetro inferior ao dos obtidos de fêmeas adultas e foram, em sua maioria, obtidos a partir de folículos pequenos (1-2mm), acredita-se que a falha em completar a maturação nuclear esteja relacionada ao crescimento incompleto desses oócitos. Os mesmos teriam menor habilidade para a progressão meiótica devido ao menor número de receptores para as gonadotrofinas, menor número de células foliculares ou ainda uma redução de fatores intrínsecos importantes para a progressão meiótica. Todos essas características poderiam também conduzir à maturação citoplasmática incompleta, a qual se refletiria em me- 
nor capacidade de desenvolvimento in vitro até o estádio de blastocisto.

Cabe ressaltar que, apesar da menor capacidade de desenvolvimento in vitro, os blastocistos obtidos a partir de oócitos de fêmeas pré-púberes apresentam aspecto morfológico [56], taxa de eclosão [43] e capacidade de desenvolvimento in vivo, isto é, taxa de prenhez e número de nascidos $[43,55]$, semelhantes aos observados para os blastocistos derivados de fêmeas adultas. Têm sido relatadas taxas de prenhez de 30 a 45\%, semelhantes às obtidas com blastocistos derivados da fecundação de oócitos coletados em fêmeas jovens e adultas, estimando em 8 a 10 o número possível de prenhezes por coleta, em fêmeas de 6 a 8 semanas de idade [2].

\section{QUALIDADE DOS EMBRIÕES OVINOS PRODUZIDOS IN VITRO}

Embriões fecundados in vitro apresentam, em geral, desenvolvimento inferior aos fecundados in vivo, independentemente do sistema de cultivo. Após cocultivo, com células do oviduto, embriões fecundados in vivo apresentaram $96 \%$ de desenvolvimento até mórula compacta, após 3 dias, e $42 \%$ de blastocistos expandidos, após 6 dias [24], índices superiores aos normalmente obtidos com embriões fecundados in vitro, nesse mesmo sistema de cultivo. Tem sido confirmada a menor habilidade em atingir o estádio de blastocisto para os zigotos ovinos produzidos in vitro, em comparação aos fecundados in vivo $[8,70]$.

De modo geral, a qualidade dos blastocistos produzidos in vitro é pouco comentada. Por avaliação morfológica, foi constatado que 20 a $30 \%$ dos blastocistos produzidos são de qualidade ruim, não sendo adequados para a transferência, independentemente do sistema de cultivo empregado $[8,11]$. Esses blastocistos de qualidade inferior possuem poucas ou nenhuma célula na Massa Celular Interna (MCI), além de índice elevado de picnoses $[8,11]$. Além disso, embriões ovinos produzidos in vitro possuem menos microvilos, trama de junções intercelulares menos intensa, maior incidência de debris celulares e maior número de gotas lipídicas que os produzidos in vivo [61].

Há poucos relatos do número de células de blastocistos produzidos in vitro e, quando efetuado, normalmente é apresentado o número médio de cé- lulas sem levar em conta o estádio do blastocisto ou a qualidade do mesmo. Após cultivo por 5-8 dias, o número total de células relatado é de 50 a 100 para os estádios de blastocisto e blastocisto expandido, de 185 para blastocisto em eclosão e de 135 a 196 para blastocisto eclodido [28,33,76,80]. Avaliando apenas os blastocistos eclodidos (BE), os quais representavam 20 a $30 \%$ do total de blastocistos produzidos 8,5 dias após a inseminação in vitro, foram efetuadas comparações [11] do número de células dos BEs obtidos em cocultivo com aqueles obtidos em cultivo no meio SOF e com tensão reduzida de oxigênio (sistema SOF-5\% $\mathrm{O}_{2}$ ). Número de células superior foi observado para o sistema SOF-5\% $\mathrm{O}_{2}$ em relação ao cocultivo, tanto para os BEs de qualidade I ou II (836 vs 570) como para os BEs de qualidade III (366 vs 263). Além disso, a superioridade do sistema SOF$5 \% \mathrm{O}_{2}$ se manifestou também por maior índice mitótico do trofoblasto e menor índice picnótico nas células do botão embrionário [11].

A sensibilidade ao congelamento dos embriões ovinos produzidos in vitro é maior do que a observada nos produzidos in vivo, sendo expressa por menores taxas de re-expansão, prenhez ou de nascimentos após a vitrificação [18,47,57,61]. Quando comparados com embriões PIV frescos, embriões ovinos PIV submetidos à vitrificação resultaram em menores taxas de prenhez [57] ou de nascimentos [58]. Embriões ovinos produzidos in vitro foram mais sensíveis à criopreservação que os embriões caprinos [74], o que tem levado a um maior interesse no estudo de fatores que possam aumentar a criotolerância dos embriões ovinos PIV $[7,45]$.

\section{TransferênCIA De EMBriões OVINOS PRODUZIDOS IN VITRO}

Os dados referentes ao desenvolvimento in vivo de embriões ovinos PIV são escassos. Além disso, há grande variação na metodologia empregada para maturação, fecundação e, sobretudo, o cultivo dos embriões, o que dificulta estabelecer quais são os índices de nascimentos considerados satisfatórios para cada sistema.

Os primeiros trabalhos de transferência (TE) de embriões ovinos fecundados in vitro foram efetuados com embriões cultivados no oviduto de ovelhas $[16,17]$. Em seguida, os embriões transferidos eram 
Tabela 2. Nascimento de cordeiros após a transferência de embriões ovinos PIV.

\begin{tabular}{lccc}
\multicolumn{1}{c}{ Sistema de cultivo } & Dias de cultivo & \% nascimentos (N/T) & Referência \\
\hline Cocultivo-cél. oviduto & 8 & $50(6 / 12)$ & 9 \\
Cocultivo-cél. oviduto & 5 & $8(2 / 26)$ & 28 \\
SOF-BSA & $7-8$ & $30(13 / 44)$ & 35 \\
SOF & 6,5 & $33(19 / 58)$ & \\
Cocultivo-cél. oviduto & & $51(39 / 77)$ & 47 \\
Oviduto (in vivo) & $6-7$ & $61(30 / 49)$ & 55 \\
SOF-BSA & $6-7$ & $38(8 / 21)$ & 58 \\
SOF-BSA & $7-8$ & $40(28 / 70)$ & 59 \\
SOF-BSA & 9 & $41(14 / 34)$ & 60 \\
SOF-BSA-SFB & 6 & $41(18 / 44)$ & 70 \\
SOF-SH & 5 & $3,3(2 / 61)$ & 79 \\
SOF-SH & 2 e 6 & $50(14 / 28)$ & $37(11 / 30)$ \\
SOF-BSA & $38(95 / 250)$ & \\
SOF-BSA & & &
\end{tabular}

cultivados in vitro, na presença ou não de células somáticas. Alguns dos resultados obtidos após a transferência de embriões ovinos PIV são apresentados na Tabela 2. Quando se trata de oócitos aspirados in vivo, dos 6 a 8 oócitos aspirados por sessão, 1 a 3 embriões são viáveis para a transferência, após FIV [21], dos quais, se transferidos a fresco, é obtida taxa de prenhez próxima de 40\% [58].

A viabilidade in vivo de embriões PIV é afetada adversamente, sendo estes um dos maiores entraves para a aplicação da técnica ou de tecnologias associadas à PIV de embriões. Os fatores responsáveis pela viabilidade reduzida dos embriões ou pelo nascimento de produtos não viáveis, após o manuseio in vitro, ainda não foram completamente elucidados.

O cultivo in vitro está geralmente associado à redução na viabilidade e sobrevivência dos embriões, mesmo para os fecundados in vivo [76]. Para embriões ovinos PIV, este aspecto é ilustrado pela redução significativa na taxa de prenhez, na sobrevivência fetal e na taxa de nascimentos, quando o tempo de cultivo aumentou de 1 para 6 dias [60]. Da mesma forma, maior número de embriões desenvolvidos foi observado 13 dias após a transferência para o oviduto, quando efetuada logo após a fecundação, em comparação com a transferência 3 ou 5 dias após [77].

A influência da origem dos embriões e do sistema de cultivo sobre a viabilidade in vivo de 190 blastocistos e de 138 mórulas transferidos para 94 e 16 fêmeas, respectivamente, constitui-se nos dados mais expressivos de transferência de embriões ovinos PIV [35]. Nesse estudo, foi constatado que embriões ovinos PIV cultivados no oviduto de ovelhas apresentaram maior sobrevivência in vivo, aos 50 dias de gestação, quando comparados com os cultivados in vitro, independentemente da presença ou não de células do oviduto. Grandes perdas na sobrevivência (38\%) foram também observadas, entre 18 e 45 dias de gestação, após a transferência de embriões ovinos PIV [28].

O estádio dos embriões tem influência na taxa de sobrevivência dos embriões produzidos in vitro, mas não na daqueles produzidos in vivo [35]. Embriões cultivados por dois dias [79] resultaram em menor porcentual de nascimentos $(24 \%$; $38 / 156)$ que aqueles cultivados por seis dias (57\%; 45/79), provavelmente pela maior seleção, que já ocorre in vitro, naqueles cultivados por mais tempo. Em termos de blastocistos, os menos avançados apresen- 
taram menor sobrevivência quando cultivados em meio SOF sem células do que quando foram cocultivados ou mantidos no oviduto [35]. Esses resultados sugerem que a escolha dos embriões para a transferência deveria ser mais rigorosa quando o cultivo é efetuado na ausência de células.

\section{Problemas gestacionais e perinatais}

Algumas anormalidades na gestação ou no nascimento têm sido associadas com a manipulação in vitro de embriões ovinos [75]. Trabalho de parto pouco intenso e aumento na duração da gestação, no peso dos cordeiros ao nascer e na mortalidade perinatal foram observados após o cultivo in vitro de embriões fecundados in vivo [76], ou quando os embriões passaram por todas as etapas de produção in vitro $[34,35,58,70,79,83]$.

A importância das condições de cultivo sobre o peso ao nascer ou crescimento exagerado dos fetos é bem documentada para embriões ovinos fecundados in vivo $[40,50,63,64]$. A presença de soro de novilho [63], de soro humano ou a realização de co-cultivo com células da granulosa [64] resultaram em maior peso fetal e maiores coeficientes alométricos para o fígado, coração e rins.

Alguns estudos têm sido efetuados na tentativa de elucidar os fatores que contribuem para a ocorrência dessas anormalidades. Pelo fato de ter sido demonstrado que altos níveis de progesterona, nos primeiros dias da gestação, conduzem ao aumento do peso ao nascer $[38,75,81]$ e crescimento anormal dos órgãos e esqueleto [38,48], a assincronia entre o ambiente uterino da receptora e o estádio do embrião poderia ser um dos fatores a interferir na ocorrência de anomalias do crescimento fetal [5], após a transferência de embriões PIV.

No entanto, as evidências sugerem que há grande contribuição das condições de cultivo in vitro sobre esse fenômeno, pois maior peso ao nascer e maior duração na gestação foram observados quando os zigotos ovinos fecundados in vitro foram cultivados na presença de soro humano, em comparação aos cultivados na presença de BSA [70]. É importante salientar que zigotos ovinos cultivados no meio SOF, acrescido de soro humano, apresentaram citoplasma com grânulos escuros e grande quantidade de vesículas lipídicas.[27,70]. Esses resultados evidenciam um provável efeito prejudicial do soro humano sobre o desenvolvimento embrionário. Há dúvidas se o soro de outras espécies também conduziria às mesmas anormalidades ou, ain$\mathrm{da}$, se a presença de soro seria prejudicial em todos os sistemas de cultivo, ou apenas quando o cultivo é efetuado em meio simples. Para Walker et al. [75], o efeito do soro poderia ocorrer diretamente sobre o genoma embrionário, sobre a fragmentação citoplasmática ou a integridade das membranas e das organelas citoplasmáticas.

Para tentar elucidar o efeito do sistema de cultivo sobre aspectos gestacionais e perinatais de embriões PIV, foram comparados [35] o cultivo em meio SOF (SOF-Cult), cocultivo com células do oviduto (Co-Cult) e cultivo no oviduto (InVivo-Cult). Surpreendentemente, os índices de mortalidade perinatal foram maiores para os cordeiros oriundos de embriões co-cultivados ou mantidos no oviduto, em comparação aos cordeiros oriundos de embriões cultivados em meio simples (Tabela 3 ). A duração da gestação foi prolongada em 4 dias em comparação ao grupo controle, independentemente dos zigotos PIV terem sido cultivados in vitro ou in vivo. $\mathrm{O}$ peso ao nascer dos cordeiros únicos, oriundos dos 3 sistemas de cultivo, foi mais elevado do que o dos cordeiros do grupo controle.

Como o emprego do cocultivo ou do cultivo no oviduto não foram suficientes para normalizar a duração da gestação, peso ao nascer e mortalidade perinatal dos embriões PIV [35], tem sido sugerido que as alterações desses parâmetros ocorrem antes da primeira divisão celular e se manifestam independentemente das condições de cultivo. Para outros, as condições de cultivo seriam determinantes pelo fato do peso ao nascer ter aumentado, tanto para cordeiros oriundos de embriões fecundados in vivo quanto para os oriundos de embriões fecundados in vitro, quando cultivados na presença de $\mathrm{SH}$, mas não quando cultivados na presença de BSA [70]. De fato, pelo menos por um curto período após fecundação, nos 3 sistemas de cultivo avaliados por Holm et al. [35], os zigotos foram expostos a altas concentrações de soro humano, o que poderia explicar a ocorrência de anormalidades, independentemente do sistema de cultivo empregado posteriormente. No entanto, o nascimento de cordeiros com peso excessivo ou anomalias congênitas, a partir de embriões com 
Tabela 3. Exemplos do efeito das condições de cultivo de zigotos ovinos PIV sobre o peso ao nascer, duração da gestação e mortalidade perinatal.

\begin{tabular}{|c|c|c|c|c|c|}
\hline \multirow{2}{*}{$\begin{array}{c}\text { Condições de } \\
\text { cultivo }\end{array}$} & \multicolumn{2}{|c|}{ Peso ao nascer (kg) } & \multirow{2}{*}{$\begin{array}{c}\text { Duração da } \\
\text { gestação (dias) }\end{array}$} & \multirow{2}{*}{$\begin{array}{l}\text { Mortalidade } \\
\text { perinatal }\end{array}$} & \multirow{2}{*}{ Referência } \\
\hline & Único & Gêmeos & & & \\
\hline SOF & $5,2^{\&}$ & 4,4 & $155^{\&}$ & $0 \%$ & 35 \\
\hline Co-Cult & $5,5^{\&}$ & 3,5 & $154^{8}$ & $21 \%$ & \\
\hline InVivo-Cult & $5,2^{8}$ & 4,4 & $154^{\&}$ & $6 \%$ & \\
\hline SOF-SH & $4,2^{\#}$ & & $147^{\$}$ & - & 70 \\
\hline SOF-BSA & 3,5 & & 145 & - & \\
\hline
\end{tabular}

2 ou 6 dias de cultivo, na ausência de soro [79], sugere que o soro não seria o único fator envolvido. É provável que todas as etapas da produção in vitro [83] e mesmo a manipulação dos embriões para a transferência (possíveis mudanças de temperatura ou pH) possam contribuir para esse fenômeno.

Tem sido especulado que as condições de cultivo e as manipulações efetuadas in vitro afetariam a regulação da transcrição de um ou mais genes importantes para o desenvolvimento embrionário precoce e a sinalização embrio-materna [75], ou outros mecanismos homeostáticos, conduzindo a alterações na expressão dos genes capazes de influenciar não somente o desenvolvimento e saúde dos neonatos mas, talvez, também dos adultos [69]. Foi confirmado que somente o alelo paterno do gene IGF2, envolvido no crescimento embrionário e fetal, se expressa na ovelha [52]. Dessa forma, cogita-se que as condições de produção in vitro de embriões poderiam perturbar o estabelecimento do imprinting e/ou expressão do gene IGF2 ou de seu receptor, contribuindo para a ocorrência de distúrbios no desenvolvimento. Não foi constatada alteração na expressão ou na concentração plasmática de IGF2, em fetos ovinos que apresentavam peso exagerado e aumento do tamanho do fígado e do coração, mas os níveis circulantes e a expressão de IGFBP2 (proteína de ligação do IGF2) foram maiores para os fetos de maior peso [82], sugerindo que a alteração na bioatividade do IGF2, em função do aumento da proteína de ligação, poderia estar implicada na síndrome do crescimento fetal exagerado.

Dentro da cadeia de produção de embriões in vitro, este aspecto assume grande importância pois o rendimento final da técnica está condicionado ao nas- cimento de produtos viáveis. Mais estudos devem ser realizados para elucidar em que momento o desenvolvimento do embrião é afetado e quais são as condições que podem contribuir para a sua ocorrência. $\mathrm{O}$ aumento da eficiência da produção in vitro dependerá da minimização desses problemas e consequente redução das perdas perinatais de cordeiros.

\section{Conclusões}

Apesar do cultivo in vitro de embriões ovinos PIV implicar em redução de 15 a $25 \%$ da viabilidade em relação ao cultivo in vivo, e da sobrevivência a termo ainda estar abaixo de $50 \%$, a produção in vitro de embriões ovinos permite a obtenção de grande número de embriões de uma mesma fêmea doadora.

Um maior emprego da produção in vitro de embriões, como ferramenta para o melhoramento genético de rebanhos ovinos, depende de alguns avanços a serem efetuados, em etapas chave desta biotécnica:

- Desenvolver sistemas que permitam a maturação de oócitos durante o transporte dos mesmos, do local de coleta até o local de realização da fecundação in vitro;

- Estabelecer protocolos para a criopreservação eficaz dos embriões PIV;

- Otimizar as condições de cultivo dos embriões de modo a reduzir as perdas gestacionais e perinatais;

- Identificar os fatores que contribuem para as diferenças entre machos, em termos de capacitação e fecundação, e estabelecer protocolos que permitam reduzir essa variação;

- Identificar os fatores que possam aumentar a competência maturacional de oócitos obtidos de fêmeas pré-púberes. 


\section{REFERÊNCIAS}

1 Anel L., Sevillano C., Alvarez M., Alegre B., Anel E., Domínguez J.C., Carbajo M.T. \& De La Fuente J. 1997. Repeated laparoscopic follicular aspiration in lambs. Theriogenology. 47: 152.

2 Armstrong D.T., Kotaras P.J. \& Earl C.R. 1997. Advances in production of embryos in vitro from juvenile and prepubertal oocytes from the calf and lamb. Reproduction, Fertility and Development. 9: 333-339.

3 Baldassare H., Castro T.E., Furnus C.C. \& De Matos D.G. 1994. In vitro maturation and fertilization of sheep oocytes collected by laparoscopic folliculocentesis. Theriogenology. 41: 159.

4 Baldassare H., Furnus C.C., De Matos D.G. \& Pessi H. 1996. In vitro production of sheep embryos using laparoscopic folliculocentesis: alternative gonadotrophin treatments for stimulation of oocyte donors. Theriogenology. 45: 707-717.

5 Barnes F.L. 2000. The effects of the early uterine environment on the subsequent development of embryo and fetus. Theriogenology. 53: 649-658.

6 Bavister B.D. 1988. Role of oviductal secretions in embryonic growth in vivo and in vitro. Theriogenology. 29: 143-154.

7 Berlinguer F., Leoni G., Bogliolo L., Pintus P.P., Rosati I., Ledda S. \& Naitana S. 2004. FSH different regimes affect the developmental capacity and cryotolerance of embryos derived from oocytes collected by ovum pick-up in donor sheep. Theriogenology. 61: 1477-1486.

8 Bernardi M.L., Cotinot C., Payen E. \& Delouis C. 1996. Transcription of Y- and X-linked genes in preimplantation ovine embryos. Molecular Reproduction and Development. 45: 132-138.

9 Bernardi M.L. \& Delouis C. 1995. Coculture of ovine zygotes fertilized in vivo or in vitro and positive effect of CZB medium on the development of in vitro fertilized zygotes. Reproduction Nutrition and Development. 35: 451-464.

10 Bernardi M.L. \& Delouis C. 1996. Sex-related differences in the developmental rate of in-vitro matured/in-vitro fertilized ovine embryos. Human Reproduction. 11: 621-626.

11 Bernardi M.L., Fléchon J-E. \& Delouis C. 1996. Influence of culture system and oxygen tension on the development of ovine zygotes matured and fertilized in vitro. Journal of Reproduction and Fertility. 106: 161-167.

12 Brackett B.G. \& Oliphant G. 1975. Capacitation of rabbit spermatozoa in vitro. Biology of Reproduction. 12: $260-274$.

13 Bredbacka K. \& Bredbacka P. 1996. Glucose controls Sex-related growth rate differences of bovine embryos produced in vitro. Journal of Reproduction and Fertility. 106: 169-172.

14 Cheng W.T.K., Moor R.M. \& Polge C. 1986. In vitro fertilization of pig and sheep oocytes matured in vivo and in vitro. Theriogenology. 25: 146.

15 Crosby I.M., Gandolfi F. \& Moor R.M. 1988. Control of protein synthesis during early cleavage of sheep embryos. Journal of Reproduction and Fertility. 82: 769-775.

16 Crozet N., Huneau D., De Smedt V., Théron M-C., Szöllösi D., Torrès S. \& Sévellec C. 1987. In vitro fertilization with normal development in the sheep. Gamete Research. 16: 159-170.

17 Czlonkowska M., Eysymont U., Guszkiewicz A., Kossakovski M. \& Dziak J. 1991. Birth of lambs after in vitro maturation, fertilization and co-culture with oviductal cells. Development. 30: 34-38.

18 Dattena M., Ptak G., Loi P. \& Cappai P. 2000. Survival and viability of vitrified in vitro and in vivo produced ovine blastocysts. Theriogenology. 53: 1511-1519.

19 Earl C.R., Irvine B.J., Kelly J.M., Rowe J.P. \& Armstrong D.T. 1995. Ovarian stimulation protocols for oocyte collection and in vitro embryo production from 8 to 9 week old lambs. Theriogenology. 43: 203.

20 Fukui Y., Glew A.M., Gandolfi F. \& Moor R.M. 1988. Ram-specific effects on in-vitro fertilization and cleavage of sheep oocytes matured in vitro. Journal of Reproduction and Fertility. 82: 337-340.

21 Galli C., Crotti G., Notari C., Turini P., Duchi R. \& Lazzari G. 2001. Embryo production by ovum pick up from live donors. Theriogenology. 55: 1341-1357.

22 Galli C. \& Moor R.M. 1991. Gonadotrophin requirements for the in vitro maturation of sheep oocytes and their subsequent embryonic development. Theriogenology. 35: 1083-1093.

23 Gandolfi F., Brevini T.A.L., Richardson L., Brown C.R. \& Moor R.M. 1989. Characterization of proteins secreted by sheep oviduct epithelial cells and their function in embryonic development. Development. 106: 303-312.

24 Gandolfi F. \& Moor R.M. 1987. Stimulation of early embryonic development in the sheep by co-culture with oviduct epithelial cells. Journal of Reproduction and Fertility. 81: 23-28.

25 Gardner D.K. \& Lane M. 1993. Amino acids and ammonium regulate mouse embryo development in culture. Biology of Reproduction. 48: 377-385. 
26 Gardner D.K., Lane M. \& Batt P. 1993. Uptake and metabolism of pyruvate and glucose by individual sheep preattachment embryos developed in vivo. Molecular Reproduction and Development. 36: 313-319.

27 Gardner D.K., Lane M., Spitzer A. \& Batt P. 1994. Enhanced rates of cleavage and development for sheep zygotes cultured to the blastocyst stage in vitro in the absence of serum and somatic cells: amino acids, vitamins and culturing embryos in groups stimulate development. Biology of Reproduction. 50: 390-400.

28 Gómez M.C., Catt J.W., Evans G. \& Maxwell W.M.C. 1998. Cleavage, development and competence of sheep embryos fertilized by intracytoplasmic sperm injection and in vitro fertilization. Theriogenology. 49: 1143-1154.

29 Guler A., Poulin N., Mermillod P., Terqui M. \& Cognié Y. 2000. Effect of growth factors, EGF and IGF-I, and estradiol on in vitro maturation of sheep oocytes. Theriogenology. 54: 209-218.

30 Gutiérrez-Adán A., Behboodi E., Anderson G.B., Medrano J.F. \& Murray J.D. 1996. Relationship between stage of development and sex of bovine IVM-IVF embryos cultured in vitro versus in the sheep oviduct. Theriogenology. 46:515-525.

31 Hill J.L., Wade M.G., Nancarrow C.D., Kelleher D.L. \& Boland M.P. 1997. Influence of ovine oviducal amino acid concentrations and an ovine oestrus-associated glycoprotein on development and viability of bovine embryos. Molecular Reproduction and Development. 47: 164-169.

32 Hill J.L., Walker S.K., Brown G.H. \& Nancarrow C.D. 1996. The effects of an estrus-associated oviductal glycoprotein on the in vitro fertilization and development of ovine oocytes matured in vitro. Theriogenology. 46: 1379-1388.

33 Holm P., Irvine B., Armstrong D.T. \& Seamark R.F. 1991. In vitro production of sheep blastocysts from IVM-oocytes using frozen semen and oviduct epithelial cell co-culture for IVF. Theriogenology. 35: 214.

34 Holm P., Walker S.K., Petersen B.A., Ashman R.J. \& Seamark R.F. 1994. In vitro vs in vivo culture of ovine IVM-IVF ova: effect on lambing. Theriogenology. 41: 217.

35 Holm P., Walker S.K. \& Seamark R.F. 1996. Embryo viability, duration of gestation and birth weight in sheep after transfer of in vitro matured and in vitro fertilized zygotes cultured in vitro or in vivo. Journal of Reproduction and Fertility. 107: 175-181.

36 Huneau D. \& Crozet N. 1989. In vitro fertilization in the sheep: effect of elevated calcium concentration at insemination. Gamete Research. 23: 119-125.

37 Kane M.T., Carney E.W. \& Ellington J.E. 1992. The role of nutrients, peptide growth factors and co-culture cells in development of preimplantation embryos in vitro. Theriogenology. 38: 297-313.

38 Kleeman D.O., Walker S.K. \& Seamark R.F. 1994. Enhanced fetal growth in sheep administered progesterone during the first three days of pregnancy. Journal of Reproduction and Fertility. 102: 411-417.

39 Kühholzer B., Müller S., Treuer A., Seregi J., Besenfelder U. \& Brem G. 1997. Repeated endoscopic ovum pick-up in hormonally untreated ewes: a new technique. Theriogenology. 48: 545-550.

40 Kuran M., Robinson J.J., Ranilla M.J., Staines M.E. \& Broadbent P.J. 1999. Incidence of fetal oversize in relation to developmental stage of in vitro cultured ovine embryos at transfer. Theriogenology. 51: 240.

41 Kuran M., Sinclair K.D., Staines M.E. \& McEvoy T.G. 1998. The effect of culture media on the development and cell number of bovine and ovine embryos. In: 50th International Congress on Animal Reproduction (Milan, Italy). p.553.

42 Lazzari G., Landriscina R., Duchi R. \& Galli C. 1995. Sex shift in calves derived from IVM-IVF embryos cultured in the sheep oviduct versus calves produced by conventional superovulation and embryo transfer. Theriogenology. $43: 263$.

43 Ledda S., Bogliolo L., Calvia P., Leoni G. \& Naitana S. 1997. Meiotic progression and developmental competence of oocytes collected from juvenile and adult ewes. Journal of Reproduction and Fertility. 109: 73-78.

44 Ledda S., Loi P., Cappai P., Filia F. \& Naitana S. 1991. Effect of glucose on early ovine embryos developed in simple serum free medium. Journal of Reproduction and Fertility [Abstract series]. 7: 8.

45 Leoni G., Bogliolo L., Berlinguer F., Rosati I., Pintus P.P., Ledda S. \& Naitana S. 2002. Defned media for vitrifcation, warming, and rehydration: effects on post-thaw protein synthesis and viability of in vitro derived ovine embryos. Cryobiology. 45: $204-212$.

46 Leoni G., Ledda S., Bogliolo L., Deledda F. \& Naitana S. 1998. Meiotic progression and protein synthesis in oocytes derived from stored $\left(17-22^{\circ} \mathrm{C}\right)$ ovaries of prepubertal and adult sheep. In: 50th International Congress on Animal Reproduction (Milan, Italy). p.557.

47 Martinez A.G., Furnus C.C., Matkovic M. \& De Matos D.G. 1997. Lambing from transfer of in vivo and in vitro produced fresh or vitrified ovine embryos. Theriogenology. 47: 351. 
48 Maxfield E.K., Sinclair K.D., Tregaskes L.D., Christensen M., Robinson J.J. \& Maltin C.A. 1996. Asynchronous embryo transfer increases muscle fibre number in ovine fetuses at day 10 of gestation. Theriogenology. 45: 226.

49 Maxwell W.M.C., Catt S.L. \& Evans G. 1996. Dose of fresh and frozen-thawed spermatozoa for in vitro fertilization of sheep oocytes. Theriogenology. 45: 261.

50 McEvoy T.G., Robinson J.J., Carolan C., Staines M.E., Broadbent P.J. \& Sinclair K.D. 1999. Ovine fetal development following embryo culture in Synthetic Oviductal Fluid with added ammonium. Theriogenology. 51: 247.

51 McGinnis L.K. \& Youngs C.R. 1992. In vitro development of ovine embryos in CZB medium. Theriogenology. 37: 559-569. 52 McLaren R.J. \& Montgomery G.W. 1999. Genomic imprinting of the insulin-like growth factor 2 gene in sheep. Mammalian Genome. 10: 588-591.

53 Morris L.H.A., Randall A.E., King W.A., Johnson W.H. \& Buckrell B.C. 2003. The contribution of the male to ovine embryogenesis in an in vitro embryo production system. Animal Reproduction Science. 75: 9-26.

54 O’Brien J.K., Beck N.F., Maxwell W.M. \& Evans G. 1997. Effect of hormone pre-treatment of prepubertal sheep on the production and developmental capacity of oocytes in vitro and in vivo. Reproduction Fertility and Development. 9: 625-631.

55 O’Brien J.K., Catt S.L., Ireland K.A., Maxwell W.M.C. \& Evans G. 1997. In vitro and in vivo developmental capacity of oocytes from prepubertal and adult sheep. Theriogenology. 47: 1433-1443.

56 O’Brien J.K., Dwarte D., Ryan J.P., Maxwell W.M.C. \& Evans G. 1996. Developmental capacity, energy metabolism and ultrastructure of mature oocytes from prepubertal and adult sheep. Reproduction Fertility and Development. 8: 1029-1037.

57 Papadopoulos S., Rizos D., Duffy P., Wade M., Quinn K., Boland M.P. \& Lonergan P. 2002. Embryo survival and recipient pregnancy rates after transfer of fresh or vitrified, in vivo or in vitro produced ovine blastocysts. Animal Reproduction Science. 74: 35-44.

58 Ptak G., Dattena M., Loi P., Tischner M. \& Cappai P. 1999. Ovum pick-up in sheep: efficiency of in vitro embryo production, vitrification and birth of offspring. Theriogenology. 52: 1105-1114.

59 Ptak G., Loi P., Dattena M., Tischner M. \& Cappai P. 1999. Offspring from One-Month-Old Lambs: Studies on the Developmental Capability of Prepubertal Oocytes. Biology of Reproduction. 61: 1568-1574.

60 Pugh P.A., Fukui Y., Tervit H.R. \& Thompson J.G. 1991. Developmental ability of in vitro matured sheep oocytes collected during the nonbreeding season and fertilized in vitro with frozen ram semen. Theriogenology. 36: 771-778.

61 Rizos D., Fair T., Papadopoulos S., Boland M.P. \& Lonergan P. 2002. Developmental, qualitative, and ultrastructural differences between ovine and bovine embryos produced in vivo or in vitro. Molecular Reproduction and Development. 62:320-327.

62 Sevillano C., Anel L., De La Fuente J., Alvarez M., Celorrio I., De Paz P., Boixo J.C. \& Olmedo J.A. 1997. In vitro development of sheep embryos derived or repeated laparoscopic folliculoaspiration. Theriogenology. 47: 298.

63 Sinclair K.D., McEvoy T.G., Carolan C., Maxfield E.K., Maltin C.A., Young L.E., Wilmut I., Robinson J.J. \& Broadbent P.J. 1998. Conceptus growth and development following in vitro culture of ovine embryos in media supplemented with bovine sera. Theriogenology. 49: 218.

64 Sinclair K.D., McEvoy T.G., Maxfield E.K., Maltin C.A., Young L.E., Wilmut I., Broadbent P.J. \& Robinson J.J. 1999. Aberrant fetal growth and development after in vitro culture of sheep zygotes. Journal of Reproduction and Fertility. 116: 177-186.

65 Songsasen N., Walmsley S., Pollard J.W., Martino A., Buckrell B.C. \& Leibo S.P. 1996. Lambs produced from cryopreserved sheep embryos derived by in vitro fertilization of aspirated oocytes. Canadian Journal of Animal Science. 76: 465-467.

66 Stangl M., Kühholzer B., Besenfelder U. \& Brem G. 1999. Repeated endoscopic ovum pick-up in sheep. Theriogenology. 52: 709-716.

67 Telford N.A., Watson A.J. \& Schultz G.A. 1990. Transition from maternal to embryonic control in early mammalian development: a comparison of several species. Molecular Reproduction and Development. 26: 90-100.

68 Tervit H.R., Whittingham D.G. \& Rowson L.E.A. 1972. Successful culture in vitro of sheep and cattle ova. Journal of Reproduction and Fertility. 30: 493-497.

69 Thompson J.G. 1997. Comparison between in vivo-derived and in-vitro produced pre-elongation embryos from domestic ruminants. Reproduction Fertility and Development. 9: 341-354.

70 Thompson J.G., Gardner D.K., Pugh P.A., McMillan W.H. \& Tervit H.R. 1995. Lamb birth weight is affected by culture system utilized during in vitro pre-elongation development of ovine embryos. Biology of Reproduction. 53: 1385-1391. 
71 Thompson J.G., Simpson A.C., Pugh P.A., Donnelly P.E. \& Tervit H.R. 1990. Effect of oxygen concentration on in-vitro development of preimplantation sheep and cattle embryos. Journal of Reproduction and Fertility. 89: 573-578.

72 Thompson J.G., Simpson A.C., Pugh P.A. \& Tervit H.R. 1992. Requirement for glucose during in vitro culture of sheep preimplantation embryos. Molecular Reproduction and Development. 31: 253-257.

73 Thompson J.G., Simpson A.C., Pugh P.A., Wright R.W. \& Tervit H.R. 1991. Glucose utilization by sheep embryos derived in vivo and in vitro. Reproduction Fertility and Development. 3: 571-576.

74 Traldi A.S., Leboeuf B., Cognié Y., Poulin N. \& Mermillod P. 1999. Comparative results of in vitro and in vivo survival of vitrified in vitro produced goat and sheep embryos. Theriogenology. 51: 175.

75 Walker S.K., Hartwich K.M. \& Seamark R.F. 1996. The production of unusually large offspring following embryo manipulation: concepts and challenges. Theriogenology. 45: 111-120.

76 Walker S.K., Heard T.M. \& Seamark R.F. 1992. In vitro culture of sheep embryos without co-culture: successes and perspectives. Theriogenology. 37: 111-126.

77 Walker S.K., Hill J.L., Kleemann D.O. \& Nancarrow C.D. 1996. Development of ovine embryos in synthetic oviductal fluid containing amino acids at oviductal fluid concentrations. Biology of Reproduction. 55: 703-708.

78 Walker S.K., Lampe R.J. \& Seamark R.F. 1989. Culture of sheep zygotes in synthetic oviduct fluid medium with different concentrations of sodium bicarbonate and hepes. Theriogenology. 32: 797-804.

79 Walmsley S.E., Buckrell B.C., Buschbeck C., Rumph N. \& Pollard J.W. 2004. Rate of abnormalities in lambs from in vitro produced embryos transferred on Day 2 compared with Day 6 postfertilization. Theriogenology. 62: 195-206.

80 Watson A.J., Watson P.H., Warnes D., Walker S.K., Armstrong D.T. \& Seamark R.F. 1994. Preimplantation development of in vitro-matured and in vitro-fertilized ovine zygotes: comparison between coculture on oviduct epithelial cell monolayers and culture under low oxygen atmosphere. Biology of Reproduction. 50: 715-724.

81 Wilmut I. \& Sales D.I. 1981. Effect of an asynchronous environment on embryonic development in sheep. Journal of Reproduction and Fertility. 61: 179-184.

82 Young L.E., Guttierez C.G., Butterwith S.C., Robinson J.J., Broadbent P.J., McEvoy T.G., Wilmut I. \& Sinclair K.D. 1999. Altered IGF binding protein expression is associated with large offspring syndrome in fetal sheep. Theriogenology. $51: 196$.

83 Young L.E, Sinclair K.D. \& Wilmut I. 1998. Large offspring syndrome in cattle and sheep. Reviews of Reproduction. 3: 155-163. 